\title{
Malignant peripheral nerve sheath tumour of the bladder associated with neurofibromatosis I
}

\author{
Julie O'Brien, $M B, B C h, B A O, F F R(R C S I) ;{ }^{*}$ Susan Aherne, $M B, B C h, B A O ;{ }^{+}$ \\ Orla Buckley, $M B, B C h, B A O, F F R(R C S l) ;{ }^{*}$ Padraig Daly, MB, BCh, BAO,; \\ William C. Torreggiani, $M B, B C h, B A O, F F R(R C S I)^{*}$
}

\begin{abstract}
Neurofibromatosis is a hamartomatous disorder of autonomic peripheral nerve sheaths associated with peripheral nerve sheath tumours. Most tumours are neurofibromas; however, the genitourinary system is rarely involved. We present a rare case of a nerve sheath tumour of the bladder in a young patient, which was discovered to be malignant.
\end{abstract}

Can Urol Assoc J 2008;2(6):637-8

A previously healthy 17 -year-old woman presented with abdominal pain and recurrent urinary tract infections. She also had intermittent difficulty passing urine and had bilateral loin discomfort. Physical examination was unremarkable aside from fullness in the suprapubic area and skin pigmentation in keeping with her known history of neurofibromatosis 1. Laboratory investigations revealed a mildly raised creatinine of $160 \mathrm{mmol} / \mathrm{L}$ and raised inflammatory markers with an erythrocyte sedimentation rate of $80 \mathrm{~mm} / \mathrm{h}$. Abdominal ultrasonography revealed moderate bilateral hydronephrosis and a pelvic mass. Computed tomography imaging confirmed a large bladder mass and showed evidence of bilateral hydronephrosis (Fig. 1). The patient subsequently had magnetic resonance imaging of her pelvis, which revealed a very large lobulated mass within the pelvis, lying anterior to the uterus and directly involving the bladder (Fig. 2). The patient underwent surgery with cystectomy and ileal conduit formation. At pathological histology, the mass was shown to be a malignant peripheral nerve sheath tumour of the bladder wall (Fig. 3 and Fig. 4).

\section{Discussion}

Neurofibromatosis is a hamartomatous disorder of autonomic peripheral nerve sheaths. It is an autosomal dominant condition with an incidence of 1 in 3000 and the genetic defect is located on chromosome 17. ${ }^{1}$ This condition generally affects the bone, nervous system, soft tissue and skin. Visceral involvement is common; however, it rarely has urological manifestations. ${ }^{2}$ It is one of the phacomatoses and the clinical features include café au lait spots, neurofibromas and Lisch nodules (pigmented iris hamartomas). Most neurofibromas originate from Schwann cells, although they may also arise from the perineurium or endoneurium. ${ }^{1}$ In such cases, nerve fibres run through the tumours, in contrast with schwannomas, in which the tumour displaces the nerve laterally. ${ }^{3}$

Malignant degeneration of a neurofibroma occurs in about $5 \%$ of cases and usually occurs in a longstanding tumour.

Histological examination reveals a tumour consisting of whorled, mucoid and solid areas, which represent a spindle cell and epithelioid cell morphology. On immunohistochemical analysis, the tumour cells are positive for vimentin and smooth muscle actin. There is focal positivity for cytokeratin (both $A E 1 / 3$ and CAM 5.2) and the tumour spindle cells are positive for CD10.

Metastases are present at presentation in $20 \%$ of cases and this usually holds a grave prognosis. The definitive treatment is surgical excision, since there is a limited response to chemotherapy.

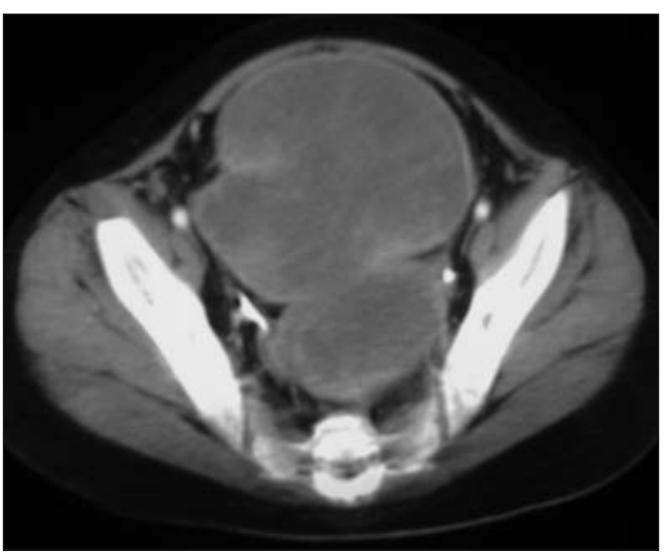

Fig. 1. Postcontrast axial computed tomography image of the lobulated mass within the bladder. 

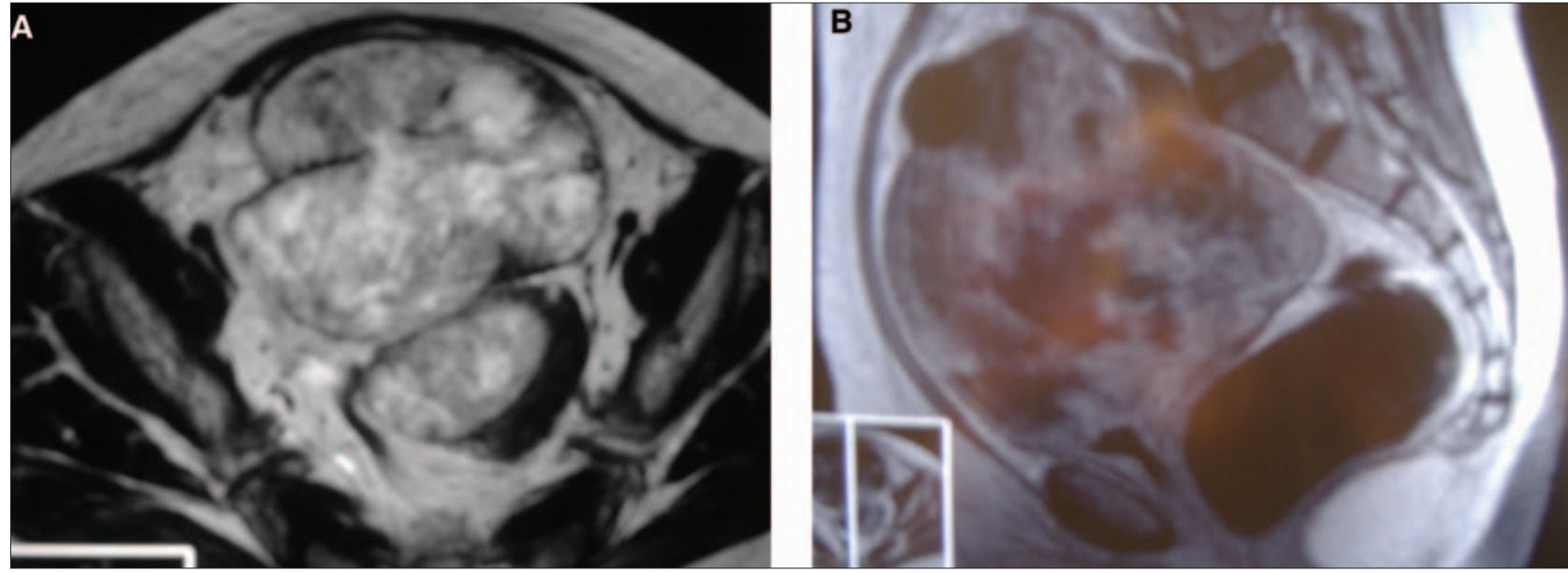

Fig. 2. Axial $T_{1}$-weighted magnetic resonance imaging demonstrating the heterogenous lobulated bladder mass (A); sagittal $T_{1}$-weighted image of the pelvis, demonstrating the extent of the heterogenous mass (B).

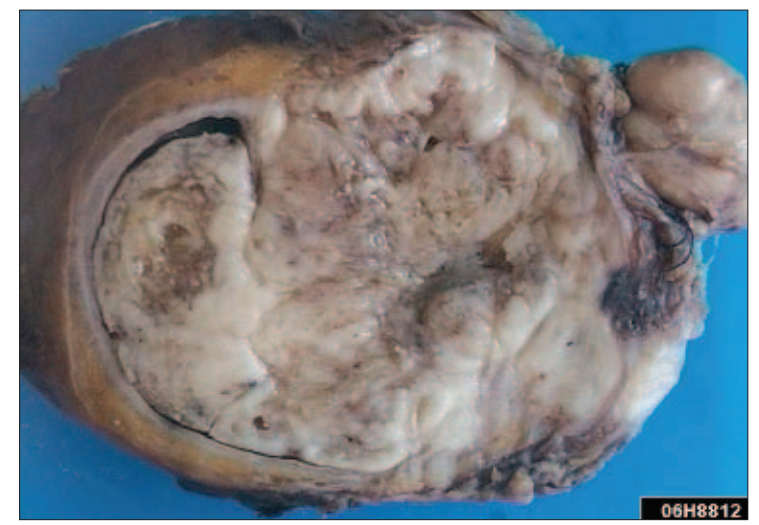

Fig. 3. Corresponding gross specimen of the bladder expanded by a large white variegated and lobulated tumour, primarily based in the bladder wall.

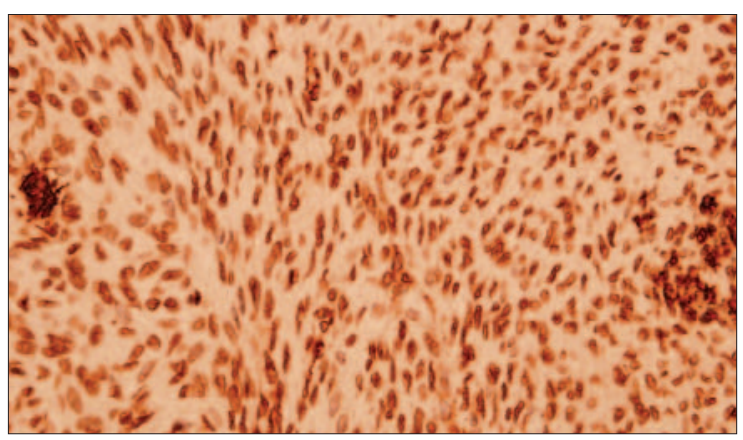

Fig. 4. Histological specimen that stains positive for smooth muscle actin confirming the diagnosis of malignant peripheral nerve sheath tumour (original magnification $\times 20$ ).
In the literature, there have been very few reported cases of urological manifestations of neurofibromatosis, and subsequent malignant degeneration is extremely rare. ${ }^{4,5}$

From the Departments of * Radiology, TPathology and fUrology, Adelaide and Meath, incorporating the National Children's Hospital, Tallaght, Dublin 24, Ireland

This article has been peer reviewed.

Competing interests: None declared.

\section{References}

1. Dahm P, Manseck A, Flossel C, et al. Malignant neurofibroma of the urinary bladder. Eur Urol 1995;27:261-3.

2. Poleksic $S$. Leiomyosarcoma of urinary bladder in von Recklinghausen's neurofibromatosis. Urology 1977;10:341-2.

3. Rober PE, Smith J, Sakr W, et al. Malignant peripheral nerve sheath tumour (malignant schwannoma) of urinary bladder in von Reckinghausen neurofibromatosis. Urology 1991;38:473-6.

4. Hulse CA. Neurofibromatosis: bladder involvement with malignant degeneration. J Urol 1990; 144:742-3.

5. Pycha A, Klingler C, Reiter W, et al. Von Recklinghausen neurofibromatosis with urinary bladder involvement. Urology 2001;58:106.

Correspondence: Dr. Julie O'Brien, Department of Radiology, Adelaide and Meath incorporating the National Children's Hospital, Tallaght, Dublin 24, Ireland; fax 00353-1-4143805; iuliemarobrien@yahoo.com 